\title{
Trends in Medicare base payment rates for hospital
}

\section{discharges, 2009-2018 [version 1; peer review: 1 approved, 1}

\section{approved with reservations]}

\author{
Zachary Rapp1, Ryan Egeland2, Frank S. David (D1 \\ ${ }^{1}$ Pharmagellan LLC, Milton, MA, 02186, USA \\ ${ }^{2}$ Cardiovascular Systems Inc., St. Paul, MN, 55112, USA
}

\author{
V1 First published: $30 \mathrm{Apr} 2019, \mathbf{8 : 6 0 5}$ \\ https://doi.org/10.12688/f1000research.18923.1 \\ Latest published: $30 \mathrm{Apr} 2019, \mathbf{8 : 6 0 5}$ \\ https://doi.org/10.12688/f1000research.18923.1
}

\section{Abstract}

Background: Under the inpatient prospective payment system (IPPS), Medicare assigns hospital discharges to medical severity-adjusted diagnosis related groups (MS-DRGs), and determines a fixed payment amount for each discharge based on its MS-DRG that is adjusted annually based on providers' reported costs. Trends in these capitated reimbursement rates may affect the incentive for manufacturers to develop drugs and devices used in inpatient care, as well as the predilection of customers (hospitals) to purchase them.

Methods: In this descriptive study, we analyzed the growth of inflation-adjusted MS-DRG base payment rates to acute care hospitals from 2009 to 2018.

Results: Inflation-adjusted base reimbursement rates for MS-DRGs in continuous existence from 2009 to 2018 ( $N=211$ ) had a median best-fit compound annual growth rate (CAGR) of $-0.26 \%$. Medical MS-DRGs exhibited a more negative median best-fit CAGR than surgical ones. Among surgical MS-DRGs, those related to musculoskeletal diagnoses had a larger median best-fit CAGR that was statistically significant compared with those associated with digestive or infectious disease diagnoses.

Conclusions: The majority of MS-DRG base payment rates for inpatient discharges have failed to keep pace with inflation, and this negative growth is more pronounced in certain clinical areas. The relationship between these reimbursement trends and decisionmaking by manufacturers and hospitals warrants further study.

\section{Keywords}

Diagnosis related group, DRG, Medicare, inpatient, hospital, reimbursement, payment

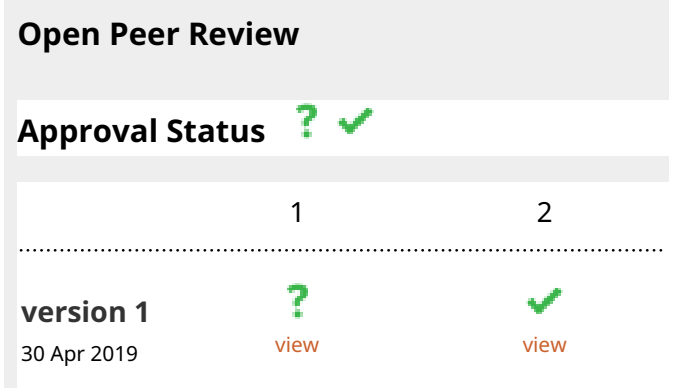

1. Allen Dobson, Dobson DaVanzo \&

Associates, LLC, Vienna, USA

2. Keith A. Joiner, University of Arizona,

Tucson, USA

Any reports and responses or comments on the article can be found at the end of the article. 
Corresponding author: Frank S. David (frank@pharmagellan.com)

Author roles: Rapp Z: Conceptualization, Data Curation, Investigation, Methodology, Writing - Review \& Editing; Egeland R:

Conceptualization, Methodology, Writing - Review \& Editing; David FS: Conceptualization, Formal Analysis, Investigation, Methodology, Supervision, Visualization, Writing - Original Draft Preparation, Writing - Review \& Editing

Competing interests: Dr. David derives virtually $100 \%$ of his income from providing consulting services to drug and device manufacturers through the advisory firm Pharmagellan; his wife is employed by and expects to receive equity in Sanofi Genzyme. In addition to his work with Pharmagellan, Dr. David is also a part-time employee of Brigham and Women's Hospital in the Brigham Research Institute. Dr. Egeland is employed by and holds equity in Cardiovascular Systems Inc. In addition to receiving income from Pharmagellan, Mr. Rapp receives income from Altoida Inc., an Alzheimer's disease diagnostics company, and Apekt Partners, a life sciences investment fund. The materials set forth in this publication are neither sponsored nor supported by any of these other firms, nor do they reflect those companies' views.

Grant information: The author(s) declared that no grants were involved in supporting this work.

Copyright: (c) 2019 Rapp Z et al. This is an open access article distributed under the terms of the Creative Commons Attribution License, which permits unrestricted use, distribution, and reproduction in any medium, provided the original work is properly cited.

How to cite this article: Rapp Z, Egeland R and David FS. Trends in Medicare base payment rates for hospital discharges, 2009-2018 [version 1; peer review: 1 approved, 1 approved with reservations] F1000Research 2019, 8:605

https://doi.org/10.12688/f1000research.18923.1

First published: 30 Apr 2019, 8:605 https://doi.org/10.12688/f1000research.18923.1 


\section{Introduction}

The Centers for Medicare and Medicaid Services (CMS) reimburses most inpatient medical and surgical discharges in the U.S. under a capitated framework known as the inpatient prospective payment system (IPPS) ${ }^{1}$. Upon discharge, a patient is assigned to a medical severity diagnosis-related group (MS-DRG) based on the nature of the patient's reason for hospitalization as well as any associated complications or comorbidities. Thus, providers are paid a fixed (capitated) rate for inpatient discharges, irrespective of the intensity of the services provided or the specific consumables (drugs or devices) utilized. This stands in contrast to ambulatory settings, where most products and services are reimbursed individually on a line-item basis.

CMS adjusts the payment rates for MS-DRGs annually ${ }^{2}$. Each MS-DRG is assigned a weight based on providers' submitted costs, which is intended to reflect the average resources expended to care for a patient in that MS-DRG, independent of region- and institution-specific factors. CMS also defines standardized base payment rates for labor, non-labor, and capital costs, which are also adjusted annually. These weights and standardized rates are used, together with institution-, region-, and case-specific modifiers, to determine a particular hospital's reimbursement for a discharge under a particular MS-DRG.

Hospital administrators use Medicare base payment rates as a significant input into their decision to adopt new products for inpatient care $^{3}$, and these rates may also influence manufacturers' investment activities across various clinical areas. However, we have not observed in the literature a comprehensive examination across MS-DRGs of how these rates have changed over time. In this descriptive study, we analyzed base payment rates from 2009 to 2018 to explore the extent to which reimbursement for individual MS-DRGs has (or has not) kept pace with inflation during this period.

\section{Methods}

Selection of MS-DRGs for inclusion

We identified all MS-DRGs in continuous existence from fiscal year 2009 (the first full year after the transition to severitybased coding and cost-based reimbursement was completed ${ }^{4}$ ) to fiscal year 2018, and assigned them to major diagnostic categories (MDCs), using CMS definitions and annual IPPS "Final Rule" data tables (e.g., these data from fiscal year [FY]2018). For years in which correction notices were issued, we used the latest (corrected) data. In order to focus on MS-DRGs with the largest clinical and budgetary relevance, we limited our analysis to those with over $\$ 100$ million in total Medicare spending in 2015 (per CMS data). Our final analysis set was comprised of 211 MS-DRGs (of the 761 MS-DRGs in existence in 2019), distributed across 21 MDCs (including "pre-MDC" and unassigned/unclassified). Our complete data file is available as Extended data.

\section{Calculation and inflation adjustment of MS-DRG base reimbursement rates}

For each year, we used available data provided by CMS to construct a "base reimbursement rate" for each MS-DRG, adapting methods described elsewhere ${ }^{5}$. We first obtained the weight of each MS-DRG from that year's Final Rule tables (e.g., Table 5 in the FY2018 document). We then calculated the sum of the standardized labor- and non-labor-related amounts (Table 1A of the FY2018 document, "meaningful use" data), plus the capital amount (Table 1D of the FY2018 document) for that year. We then multiplied this total dollar amount by the MS-DRG's weight to obtain a value for the base reimbursement rate in nominal dollars.

We adjusted each MS-DRG's base reimbursement rate from nominal dollars to constant (January 2009) dollars by using the CPI-U calculator provided by the Bureau of Labor Statistics.

\section{Determination of best-fit MS-DRG reimbursement growth rates}

For each MS-DRG, we determined the "best fit" compound annual growth rate (CAGR) ( $r$ in the best-fit exponential line equation $\left[y=a(1+r)^{x}\right]$ ), which we refer to as the "best-fit CAGR" in the remainder of this article. Compared with standard CAGR calculations, which use just the starting and ending reimbursement rates, this approach takes into account all of the observed values over the time period. We also calculated each MS-DRG's "expected" reimbursement rate by year, based on the derived slope and intercept of its best-fit line, in order to calculate the coefficient of determination $\left(\mathrm{R}^{2}\right)$ between the calculated best-fit exponential equation values and the observed reimbursement rates.

\section{Mathematical tools and statistical tests}

We examined differences in best-fit CAGR between subsets of MS-DRGs with the Kruskal-Wallis test (on MDCs containing five or more MS-DRGs), and confirmed statistically significant results with post hoc pairwise comparisons (Dunn test with Bonferroni correction). All mathematical calculations and statistical analyses were performed using Microsoft Excel (see here and here).

\section{Results}

From FY2009 to FY2018, inflation-adjusted MS-DRG base reimbursement rates had a median best-fit CAGR of $-0.26 \%$ (interquartile range [IQR], $-0.89 \%$ to $0.47 \%$ ) (Table 1 ) . Over the analyzed time period, 59.2\% (125/211) of MS-DRGs had negative best-fit CAGRs. In bivariate models, the variability in the best-fit CAGRs of individual MS-DRGs was not explained by either the 2015 Medicare spending level or 2018 inflation-adjusted base reimbursement rate (Figure 1; $R^{2}<0.02$ for each).

Medical MS-DRGs exhibited a more negative median bestfit CAGR than surgical ones $(-0.57 \%$ vs. $-0.14 \%$; adjusted $H=5.631, \mathrm{df}=1, \quad p=0.018$ via Kruskal-Wallace). A total of

axamination of $R^{2}$ values across all MS-DRGs suggested that for most of them, the calculated best-fit CAGR explained a sizable fraction of the observed variability in reimbursement rates (mean $R^{2} 0.58$, standard deviation 0.32 ). 


\begin{tabular}{|c|c|c|c|c|}
\hline \multirow[t]{2}{*}{ MS-DRGs } & \multirow[t]{2}{*}{ N } & \multicolumn{2}{|r|}{ CAGR } & \multirow{2}{*}{$\begin{array}{c}\% \text { of MS-DRGs } \\
\text { with CAGR }<0 \%\end{array}$} \\
\hline & & Median & IQR & \\
\hline All MS-DRGs in analysis set & 211 & $-0.29 \%$ & $-1.14 \%, 0.47 \%$ & $59 \%(125 / 211)$ \\
\hline MDC 01 (nervous system) & 23 & $-0.65 \%$ & $-2.05 \%, 0.35 \%$ & $65 \%(15 / 23)$ \\
\hline MDC 04 (respiratory) & 22 & $-1.11 \%$ & $-1.58 \%,-0.53 \%$ & $86 \%(19 / 22)$ \\
\hline MDC 05 (circulatory) & 45 & $-0.16 \%$ & $-1.07 \%, 0.54 \%$ & $56 \%(25 / 45)$ \\
\hline MDC 06 (digestive) & 22 & $-0.93 \%$ & $-1.79 \%,-0.15 \%$ & $82 \%(18 / 22)$ \\
\hline MDC 07 (hepatobiliary/pancreatic) & 13 & $-0.61 \%$ & $-1.14 \%, 0.09 \%$ & $85 \%(11 / 13)$ \\
\hline MDC 08 (musculoskeletal system and connective tissue) & 30 & $0.47 \%$ & $-0.04 \%, 0.98 \%$ & $27 \%(8 / 30)$ \\
\hline MDC 10 (endocrine, nutritional, and metabolic) & 6 & $-0.17 \%$ & $-0.68 \%, 0.34 \%$ & $67 \%(4 / 6)$ \\
\hline MDC 11 (kidney and urinary tract) & 12 & $-0.22 \%$ & $-1.60 \%, 0.57 \%$ & $58 \%(7 / 12)$ \\
\hline MDC 16 (hematologic and immune) & 5 & $0.31 \%$ & $-0.06 \%, 1.97 \%$ & $20 \%(1 / 5)$ \\
\hline MDC 18 (infectious and parasitic diseases) & 8 & $-1.38 \%$ & $-1.66 \%,-0.84 \%$ & $100 \%(8 / 8)$ \\
\hline MDC 21 (injuries, poisonings, and toxic drug effects) & 5 & $0.27 \%$ & $-0.44 \%, 1.52 \%$ & $20 \%(1 / 5)$ \\
\hline Medical MS-DRGs & 108 & $-0.62 \%$ & $-1.40 \%, 0.31 \%$ & $67 \%(72 / 108)$ \\
\hline MDC 01 (nervous system) & 16 & $-0.94 \%$ & $-2.07 \%, 0.30 \%$ & $69 \%(11 / 16)$ \\
\hline MDC 04 (respiratory) & 17 & $-1.29 \%$ & $-1.75 \%,-0.62 \%$ & $82 \%(14 / 17)$ \\
\hline MDC 05 (circulatory) & 18 & $-0.63 \%$ & $-1.28 \%, 0.64 \%$ & $67 \%(12 / 18)$ \\
\hline MDC 06 (digestive) & 14 & $-0.93 \%$ & $-1.79 \%, 0.05 \%$ & $71 \%(10 / 14)$ \\
\hline MDC 07 (hepatobiliary/pancreatic) & 8 & $-0.71 \%$ & $-1.20 \%,-0.08 \%$ & $88 \%(7 / 8)$ \\
\hline MDC 11 (kidney and urinary tract) & 6 & $-1.12 \%$ & $-2.39 \%,-0.02 \%$ & $83 \%(5 / 6)$ \\
\hline MDC 16 (hematologic and immune) & 5 & $0.31 \%$ & $-0.06 \%, 1.97 \%$ & $20 \%(1 / 5)$ \\
\hline Surgical MS-DRGs & 103 & $-0.11 \%$ & $-0.77 \%, 0.55 \%$ & $51 \%(53 / 103)$ \\
\hline MDC 01 (nervous system) & 7 & $-0.22 \%$ & $-1.28 \%, 0.51 \%$ & $57 \%(4 / 7)$ \\
\hline MDC 04 (respiratory) & 5 & $-0.65 \%$ & $-1.26 \%,-0.42 \%$ & $100 \%(5 / 5)$ \\
\hline MDC 05 (circulatory) & 27 & $0.02 \%$ & $-0.50 \%, 0.49 \%$ & $48 \%(13 / 27)$ \\
\hline MDC 06 (digestive) & 8 & $-0.90 \%$ & $-2.11 \%,-0.30 \%$ & $100 \%(8 / 8)$ \\
\hline MDC 07 (hepatobiliary/pancreatic) & 5 & $-0.61 \%$ & $-1.00 \%, 0.37 \%$ & $80 \%(4 / 5)$ \\
\hline MDC 08 (musculoskeletal system and connective tissue) & 26 & $0.47 \%$ & $0.06 \%, 0.98 \%$ & $23 \%(6 / 26)$ \\
\hline MDC 11 (kidney and urinary tract) & 6 & $0.40 \%$ & $-0.50 \%, 1.02 \%$ & $33 \%(2 / 6)$ \\
\hline MDC 18 (infectious and parasitic diseases) & 5 & $-1.50 \%$ & $-2.22 \%,-1.02 \%$ & $100 \%(5 / 5)$ \\
\hline
\end{tabular}

$I Q R$, interquartile range.

$66 \%$ of medical MS-DRGs exhibited negative best-fit CAGRs (71/108), compared with 52\% (54/103) of surgical ones.

In total, 11 MDCs were comprised of five or more MSDRGs, and thus were suitable for further analysis. We found a statistically significant difference in median best-fit CAGRs between MDCs (adjusted $H=63.128, \mathrm{df}=10, \quad p=9.23 \times 10^{-10}$ via Kruskal-Wallace). Upon pairwise analysis (Dunn with Bonferroni correction), we determined that the best-fit CAGRs of MS-DRGs for musculoskeletal diagnoses (MDC 08) were statistically significantly larger than that of MS-DRGs for nervous, respiratory, digestive, or infectious diseases (MDCs 01, 04, 06, and 18, respectively) (Table 2).

One plausible explanation for differences in median best-fit CAGRs could be the relative fraction of surgical MS-DRGs (which have higher growth) in different therapeutic areas; indeed, the musculoskeletal MDC is substantially enriched for surgical MS-DRGs (25/29 (86\%), compared with 103/211 (49\%) in the overall sample). Thus, we re-analyzed median best-fit CAGRs across MDCs after first separating medical MS-DRGs from surgical ones. There were eight MDCs comprised of 89 


\section{CAGR vs. 2018 base reimbursement rate}

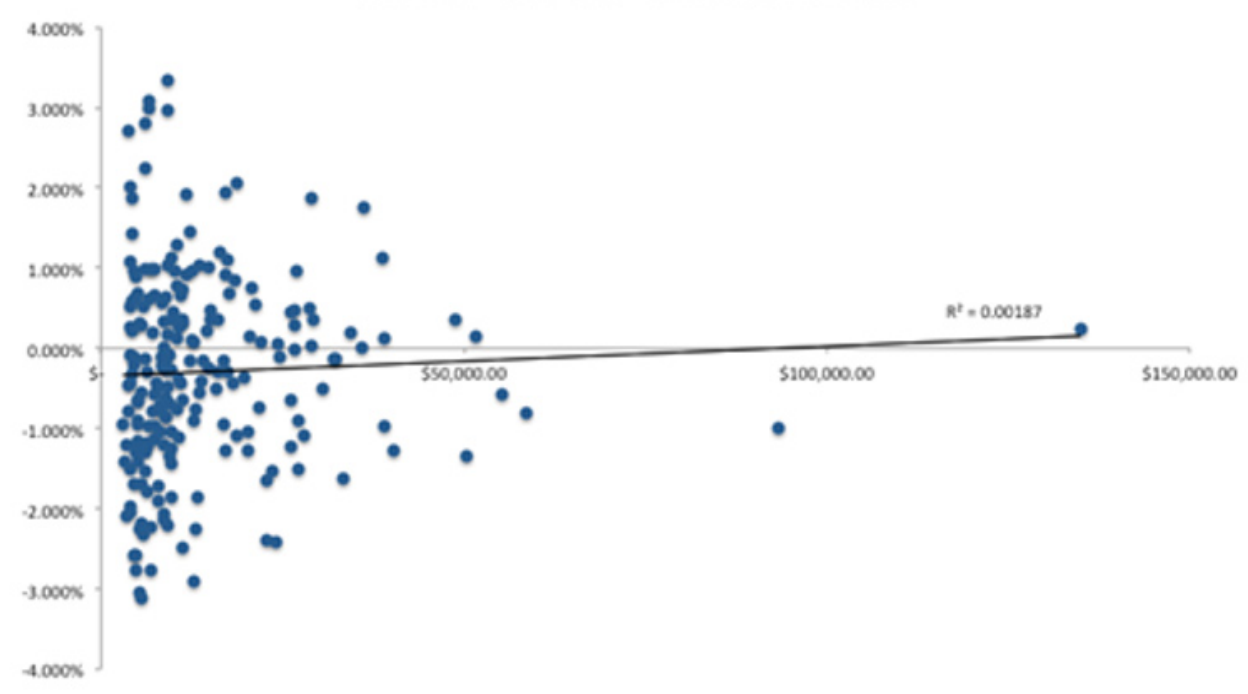

CAGR vs. 2015 Medicare spend

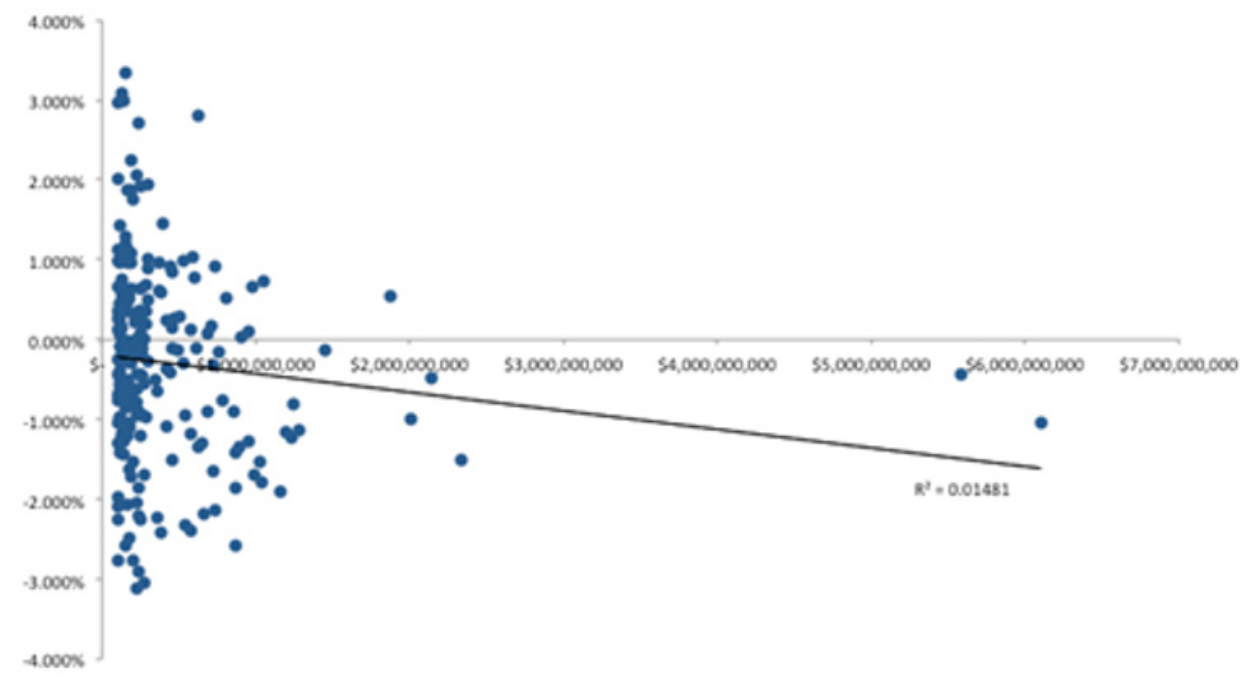

Figure 1. Relationship between 2018 base reimbursement rate (top) or 2015 Medicare spending (bottom) and best-fit compound annual growth rates (CAGRs). Each circle represents one medical severity diagnosis-related group. Best-fit line with $R^{2}$ is shown in each scatter plot.

surgical MS-DRGs, and seven MDCs comprised of 84 medical MS-DRGs, suitable for analysis (i.e., comprised of five or more MS-DRGs).

Looking only at surgical MS-DRGs, we found a statistically significant difference in median best-fit CAGRs between MDCs (adjusted $H=32.465, \mathrm{df}=7, p=3.3 \times 10^{-5}$ by Kruskal-Wallace), and on pairwise analysis, we confirmed that the median best-fit CAGR for surgical MS-DRGs for musculoskeletal diagnoses (MDC 08) was statistically significantly larger than that for digestive and infectious ones (MDCs 06 and 18, respectively) (Table 3). Looking only at medical MS-DRGs, we failed to identify a statistically significant difference in median best-fit CAGRs between MDCs (adjusted $H=11.129$, $\mathrm{df}=6, p=0.084$ by Kruskal-Wallace).

\section{Discussion}

Under the IPPS, Medicare annually adjusts base payment rates for inpatient discharges based on providers' reported costs. In this descriptive study, we observed that the majority of MS-DRG base payment rates have failed to keep pace with inflation. We also observed that reimbursement rates for medical discharges have declined more rapidly than those for surgical ones, and within surgery, reimbursement for orthopedics-related discharges has grown more rapidly than reimbursement for gastrointestinal or infectious disease discharges.

The IPPS is intended to contain health care spending by encouraging hospitals to reduce costs and increase efficiency, and it has been largely effective at achieving that aim ${ }^{6}$. That success is a double-edged sword, however. Capitated payments encourage 
Table 2. Dunn's test for multiple pairwise comparisons across major diagnostic categories (MDCs) (all medical severity diagnosis-related groups). Corrected $P$ values for post hoc pairwise comparisons of growth rates for best-fit compound annual growth rates by MDC. Statistically significant results $(P<0.05)$ indicated in italics.

\begin{tabular}{|c|c|c|c|c|c|c|c|c|c|c|}
\hline & MDC 04 & MDC 05 & MDC 06 & MDC 07 & MDC 08 & MDC 10 & MDC 11 & MDC 16 & MDC 18 & MDC 21 \\
\hline MDC 01 & 7.5 & 9.3 & 17 & 55 & 0.0081 & 18 & 26 & 1.4 & 5.1 & 3.2 \\
\hline MDC 04 & & 0.12 & 36 & 11 & 0.0000054 & 3.0 & 2.8 & 0.099 & 30 & 0.30 \\
\hline MDC 05 & & & 0.61 & 15 & 0.16 & 46 & 43 & 6.1 & 0.37 & 12 \\
\hline MDC 06 & & & & 21 & 0.000069 & 5.7 & 6.3 & 0.24 & 20 & 0.67 \\
\hline MDC 07 & & & & & 0.086 & 20 & 29 & 2.0 & 6.9 & 4.2 \\
\hline MDC 08 & & & & & & 9.5 & 1.1 & 50 & 0.00067 & 44 \\
\hline MDC 10 & & & & & & & 39 & 15 & 2.0 & 23 \\
\hline MDC 11 & & & & & & & & 6.2 & 2.1 & 11 \\
\hline MDC 16 & & & & & & & & & 0.092 & 43 \\
\hline MDC 18 & & & & & & & & & & 0.25 \\
\hline
\end{tabular}

Table 3. Dunn's test for multiple pairwise comparisons across major diagnostic categories (MDCs) (surgical medical severity diagnosis-related groups only). Corrected $P$ values for post hoc pairwise comparisons of growth rates for best-fit compound annual growth rates by MDC. Statistically significant results $(P<0.05)$ indicated in italics.

\begin{tabular}{|l|r|r|r|r|r|r|r|}
\hline & MDC 04 & MDC 05 & MDC 06 & MDC 07 & MDC 08 & MDC 11 & MDC 18 \\
\hline MDC 01 & 6.8 & 17 & 3.9 & 21 & 1.6 & 7.9 & 1.2 \\
\hline MDC 04 & & 1.8 & 25 & 12 & 0.063 & 1.0 & 12 \\
\hline MDC 05 & & & 0.40 & 11 & 0.92 & 11 & 0.11 \\
\hline MDC 06 & & & & 8.8 & 0.0028 & 0.33 & 13 \\
\hline MDC 07 & & & & & 1.2 & 5.4 & 3.2 \\
\hline MDC 08 & & & & & & 18 & 0.0012 \\
\hline MDC 11 & & & & & & & 0.089 \\
\hline
\end{tabular}

hospitals to adopt new technologies that boost efficiency or directly enable overall cost savings, and discourage them from purchasing those that accomplish neither of these aims; however, that latter group may include products that improve patient care in ways that are not clearly reflected on institutions' financial balance sheets, while increasing hospitals' $\operatorname{costs}^{7-9}$. The extent to which declining reimbursement rates for many MS-DRGs further exacerbates these behaviors warrants further study.

Federal programs and policies exist to help offset expenses that exceed MS-DRG payments, but available evidence suggests their impact is limited ${ }^{10}$. Medicare's new technology add-on program (NTAP) is only available for products that meet stringent criteria for economic and clinical impact, and only 19 drugs and devices in total were approved for supplemental payments through this mechanism from 2001 to $2015^{11}$. Thus, in many cases, particularly for technologies with an intermediate level of added cost and benefit, increased expenses for inpatient discharges are borne by providers without additional compensation beyond that derived from the MS-DRG reimbursement formula.

In addition to affecting hospitals' behavior, declining reimbursement rates may reduce the economic incentive to develop new drugs or devices for inpatient care. Numerous empirical economic studies (including those cited here and here) in the pharmaceutical industry have shown a positive relationship between R\&D spending (and output) and market opportunity $\operatorname{size}^{12-15}$. As noted above, this phenomenon may be particularly significant for new products that provide benefits to patients and hospitals that are difficult to quantify, as well as those that fail to meet the clinical and financial criteria to quality for add-on payments. Further work, building on the descriptive analysis 
presented here, is warranted to examine in more detail the relationship between new product development for inpatient care and reimbursement growth rates.

An important consideration regarding the interpretation of MS-DRG payment trends relates to the distinction between gross (top-line) reimbursement, which is measured in this study, and net (bottom line) profitability. It is entirely possible that some MS-DRGs with flat or declining reimbursement can still be highly profitable compared to others with increasing payment levels, if hospital costs can be disproportionately reduced. In theory, profitability, not reimbursement, should dictate the attractiveness of developing and purchasing drugs and devices for inpatient use under a given MS-DRG. In practice, however, we believe payment levels do, in fact, influence the perceptions-and, ultimately, the behaviors-of manufacturers and hospitals. Anecdotal evidence suggests that hospitals rarely have insight into the profitability of specific inpatient procedures (illustrated here and here), and often base purchasing decisions on payment levels ${ }^{16}$. Similarly, in our professional experience with medical device executives, we have found that calculations of reimbursement rate trends like the ones performed here are a key component of investment decisions around developing and commercializing inpatient care products.

This work has some additional limitations. First, the base reimbursement rates for each MS-DRG we determined do not precisely reflect the amounts that particular institutions receive, due to adjustments for factors like low socioeconomic status in a hospital's catchment area and the institution's involvement in graduate medical education. Thus, a specific hospital may experience different MS-DRG reimbursement rates and growth trends than the ones calculated here. Second, reimbursement rates by private payers may not follow exactly the same trends as those described here. Non-Federal payers typically reimburse at rates above Medicare ${ }^{17}$, but trends for individual MS-DRGs have not been comprehensively examined. Third, since 2015, some Medicare providers have opted to participate in bundled payment programs for inpatient and post-hospitalization care in some clinical areas instead of the IPPS, so their reimbursement rates for some MS-DRGs may not be accurately reflected by the data analyzed here. This is particularly relevant for surgical MS-DRGs for musculoskeletal discharges (MDC 08), for which we observed larger reimbursement growth than other surgical MS-DRGs, because this MDC includes many procedures that are now covered by bundled payments. In summary, although the data presented here are generally applicable, the experience of a particular hospital depends on factors specific to its payer mix, geography, and other factors.

Notwithstanding its limitations, our analysis is the first to calculate trends in inflation-adjusted Medicare base reimbursement rates for inpatient discharges across individual MS-DRGs. We show here that since 2009, these reimbursement rates have declined for a substantial fraction of MS-DRGs, particularly for medical discharges as compared with surgical ones, and that reimbursement for musculoskeletal discharges appears to have been relatively spared compared with some other surgical domains. To the extent that manufacturers and hospitals use these rates to guide their investment decisions, the IPPS may unintentionally promote or disincentivize innovation and commercial uptake in specific clinical areas. The relationship between these reimbursement trends, new product development, and market adoption in inpatient care warrants further study.

\section{Data availability}

Underlying data

MS-DRG weights, standardized reimbursement amounts, and 2015 total Medicare payments by MS-DRG were obtained from Final Rule tables for 2009-2018 from the website of the Center for Medicare and Medicaid Services (CMS).

These data are publicly available from CMS, without any restrictions.

\section{Extended data}

Open Science Framework: MS-DRG data and analysis. https:// doi.org/10.17605/OSF.IO/FKMYA.

This project contains Supplemental File 1: "MS-DRG data and analysis"

Extended data are available under the terms of the Creative Commons Zero "No rights reserved" data waiver (CC0 1.0 Public domain dedication).

Grant information

The author(s) declared that no grants were involved in supporting this work.

\section{Acknowledgements}

We thank Julie Lin for helpful comments, and Emily Villas for assistance with data collection.
1. Payments to hospitals for inpatient hospital services. 42 U.S.C. $§ 1395 w w$ Reference Source

2. Department of Health and Human Services, Office of Evaluation and Inspections: Medicare hospital prospective payment system: How DRG rates are calculated and updated. August 2001. OEI-09-00-00200. accessed March 26, 2019. Reference Source
3. Egeland RD, Rapp Z, David FS: From innovation to market adoption in the operating room: The "CFO as customer". Surgery. 2017; 162(3): 477-482. PubMed Abstract | Publisher Full Text

4. Medicare program; proposed changes to the hospital inpatient prospective payment systems and fiscal year 2009 rates, 42 Fed. Reg. 23528. (April 30, 2008). Reference Source 
5. Krinsky S, Ryan AM, Mijanovich T, et al.: Variation in Payment Rates under Medicare's Inpatient Prospective Payment System. Health Serv Res. 2017 52(2): 676-696.

PubMed Abstract | Publisher Full Text | Free Full Text

6. Medicare Payment Advisory Commission (MedPAC): Report to Congress: Medicare and the health care delivery system. 2019. accessed April 5, 2019 Reference Source

7. Sorenson C, Drummond M, Torbica A, et al.: The role of hospital payments in the adoption of new medical technologies: an international survey of current practice. Health Econ Policy Law. 2015; 10(2): 133-159. PubMed Abstract | Publisher Full Text

8. Freedman S: Health insurance and hospital technology adoption. Adv Health Econ and Health Serv Res. 2012; 23: 177-198. PubMed Abstract | Publisher Full Text

9. Scheller-Kreinsen D, Quentin W, Busse R: DRG-based hospital payment systems and technological innovation in 12 European countries. Value Health. 2011; 14(8): 1166-1172.

PubMed Abstract | Publisher Full Text

10. Clyde A, Bockstedt L, Farkas JA, et al:: Experience with Medicare's new technology add-on payment program. Health Aff (Millwood). 2008; 27(6): 1632-1641

PubMed Abstract | Publisher Full Text

11. Hernandez J, Machacz SF, Robinson JC: US hospital payment adjustments for innovative technology lag behind those in Germany, France, and Japan. Health Aff (Millwood). 2015; 34(2): 261-270.

PubMed Abstract | Publisher Full Tex

12. Acemoglu $D$, Linn J: Market size in innovation: Theory and evidence from the pharmaceutical industry. Quart J Econ. 2004; 119(3): 1049-1090. Publisher Full Text

13. Blume-Kohout ME, Sood N: Market size and innovation: Effects of Medicare Part D on pharmaceutical research and development.

J Public Econ. 2013; 97: 327-336. PubMed Abstract | Publisher Full Text | Free Full Text

14. DuBois P, Mouzon O, Scott-Morton F, et al:: Market size and pharmaceutical innovation. RAND J Econ. 2015; 46: 844-871. Publisher Full Text

15. Bruen B, Docteur E, Lopert R, et al:: The impact of reimbursement policies and practices on healthcare technology innovation. Office of the Assistant Secretary for Planning and Evaluation. U.S. Department of Health and Human Services. 2016. accessed November 14, 2018. Reference Source

16. Egeland RD, Rapp Z, David FS: From innovation to market adoption in the operating room: The "CFO as customer". Surgery. 2017; 162(3): 477-482. PubMed Abstract | Publisher Full Text

17. Maeda J: An analysis of hospital prices for commercial and Medicare Advantage plans. Congressional Budget Office. 2017. accessed March 8, 2019. Reference Source 


\section{Open Peer Review}

\section{Current Peer Review Status:}

\section{Version 1}

Reviewer Report 18 February 2020

https://doi.org/10.5256/f1000research.20743.r59104

(C) 2020 Joiner K. This is an open access peer review report distributed under the terms of the Creative Commons Attribution License, which permits unrestricted use, distribution, and reproduction in any medium, provided the original work is properly cited.

\section{Keith A. Joiner}

Center for Management Innovations in Health Care, Eller College of Management, University of Arizona, Tucson, AZ, 85724, USA

19th March 2020 - This report was updated at the request of the reviewer, as they wished to include further information in their review.

The authors do a careful and well-informed analysis of the CAGR for base MS-DRG over the period from 2009-2018. While the overall trend of a $0.26 \%$ decrease in CAGR over this time frame is useful information, the comparison across MDCs provides more insight, and potentially actionable information.

Having said this, the author's implication that such results have or could have substantial impacts on hospital decision making seem exaggerated. This is particularly true in the current environment of CMS metrics for hospitals, where hospitals can lose up to $6 \%$ of total Medicare revenues annually through the hospital readmissions reduction program (HRRP), the hospital acquired conditions program (HAC), and the hospital value-based purchasing program (VBP). Similarly, hospital can earn bonuses if they are top performers in these categories. In other words, the financial implications and consequences of these programs far outstrip small decreases (or increases) in base MS-DRG rates, and as such have a much greater impact on hospital decision making.

As more specifically related to the data in this manuscript, the case mix index for hospitals has been steadily rising over the time period of this study. This indicates that, despite small declines in the base MS-DRG, the patient mix at hospitals is increasing in complexity, and accordingly in reimbursements. This is occurring through two mechanisms. Disproportionately more patients with higher base MS-DRG are being hospitalized. In addition, the mix of admitted patients with MS-DRG weights with either complicating conditions (CC) or major complicating conditions (MCC) is increasing. Both mechanisms are more than offsetting the small declines in base MS-DRG. Hospital decisions on investment or resource allocation as related to MS-DRG will be based on the patient mix, and not on changes in base MS-DRG. 
Is the work clearly and accurately presented and does it cite the current literature?

Yes

Is the study design appropriate and is the work technically sound?

Yes

Are sufficient details of methods and analysis provided to allow replication by others?

Yes

If applicable, is the statistical analysis and its interpretation appropriate?

Yes

Are all the source data underlying the results available to ensure full reproducibility?

Yes

Are the conclusions drawn adequately supported by the results?

Partly

Competing Interests: No competing interests were disclosed.

Reviewer Expertise: Health economics, health care payment reform.

I confirm that I have read this submission and believe that I have an appropriate level of expertise to confirm that it is of an acceptable scientific standard.

Reviewer Report 22 November 2019

https://doi.org/10.5256/f1000research.20743.r54919

(C) 2019 Dobson A. This is an open access peer review report distributed under the terms of the Creative Commons Attribution License, which permits unrestricted use, distribution, and reproduction in any medium, provided the original work is properly cited.

\author{
Allen Dobson \\ Dobson DaVanzo \& Associates, LLC, Vienna, VA, USA
}

Q-1)

There are a few technical terminology errors that should be corrected. MS-DRG weights are based on relative resource use (costs) for each MS-DRG. Overall provider costs are never used; either in weight calculations or in charging the base payment amounts one year to the next unless the system is recalibrated (setting payments to costs) over time. MS-DRG weights are not "capitated" amounts for a given person; they are prospective payment amounts set for each case as defined by individual MS-DRGs. MS-DRGs are Medicare-Severity - DRGs, not Medical severity - DRGs, and as I say below, CMS does not use CPI-U as its inflation adjustor for healthcare costs. It uses the hospital market bracket (MB) for this purpose. 


\section{$\underline{Q}-2)$}

The study design would be more accurate if the hospital MB were used, as opposed to the CPI-U, as the study price deflector. The hospital MB was designed in this purpose and is used by CMS exclusively in its payment system design and calibration. The paper notes that surplus financial capacity comes from profits (margins), not absolute payment amounts. Low payments that are profitable, are more conducive for product development than higher paid MS-DRGs that are big losers in terms of margin (profits).

Along these lines, I did not see in the paper a mention of payment "compression". That is, high cost cases tend to be underpaid and low-cost cases are overpaid in case-mix-based payment systems. This would seem to be important to understanding the relative payment growth in case types across time. That is, high cost cases that are underpaid initially may set better payment rules over time.

\section{$\underline{Q-4 / 6)}$}

The analysis indicates that CMS IPPS (inpatient prospective payment) payments lag behind the payment rates one year to the next. This is not in and of itself news. It is well known that MB and productivity cuts, Medicare DSH payment reductions, and hospital quality penalties reduce the rate of increase in IPPS case payments well below MB growth rates. The distinction between MSDRG types (Medical vs. Surgical) is somewhat novel and worth presenting, but some information for why this happens would be useful. An example of the payment dollars involved over 2 to 3 years might also be useful.

The focus on underpayments thwarting innovation and new product development and diffusion is likely directionally correct, but as the paper notes, this is more an issue of MS-DRG profitability relative to costs, as opposed to absolute payment amounts. I would argue that device manufacturers know which MS-DRGs are profitable and which are not. I have worked with a few larger companies and they know which MS-DRGs by hospital are profitable. Admittedly, smaller companies do not have the Medicare cost report skills to make these calculations. Additionally, many hospitals also know which services are profitable (e.g. cardiology and orthopedics). But, nevertheless, as payments fall relative to costs over time the downward pressure on product innovation and diffusion must intensify as the paper states.

The hospital outpatient side of the payment equation must be somewhat less harmful to product innovation to the extent that APGs are based on relative input costs on a more or less real time basis. The paper notes this, but does not indicate that OP PPS bundles clinically comparable procedures within the same APG. Thus, high cost procedures in low payment ARGs are less well paid.

As noted, the CPI-U is not the measure of inflation used by CMS for hospital input factor price inflation. CMS uses the hospital market bracket developed specifically for hospital payments. More properly the paper should use MB not CPI-U as its price deflector. Some might argue this is a critical flaw in the paper. I would have thought the differences between payments and inflation would have been larger then reported. 
That said, the study contention that CMS IPPS does not keep up with inflation is undoubtedly directionally correct. And the study's distinction between medical and surgical cases is also likely directionally correct, unless the CMS MB and CPI-U price medical and surgical service inputs differently. I would guess this is unlikely.

Note: Providers' reported costs should be reported as providers reported relative MS-DRG costs. A given providers' absolute MS-DRG costs are not covered under CMS- IPPS by design.

The notion of product value (e.g. some services may reduce overall healthcare costs - (e.g. drugs may reduce hospital costs) is well taken, but this is more of a coverage issue then an issue that will be explicitly accounted for in a payment system. CMS IPPS covers average production costs with no regard for internal MS-DRG overall system efficiency. If a product is covered, it is paid for.

Given the finding that Medical MS-DRGs are paid relatively less well over time, as compared to surgical MS-DRGs, one would expect either that medical MS-DRG are more efficiently provided over time (better medicines, diagnoses, and therapies) or cost accounting in the Medicare Cost Report undervalues Medicaid MS-DRG relative cost over time. The CMS IPPS is not developed to favor one MS-DRG type over another. So it may be that the Medical MS-DRGs worse position in keeping up with inflation reflects productivity growth, not declining profits. If so, the paper's conclusion is challenged.

\section{Summary}

I was the research director for Medicare when IPPS was developed and implemented in 1983. Device manufacturers frequently came unto CMS and recited the arguments presented in this paper. Over the years, I have not heard that CMS IPPS has stalled innovation. Probably because Academic Medical Centers have been relatively well paid under IPPS. The arguments against IPPS are more frequently related to quality; hence the CMS emphasis on quality measures and penalties as it develops its prospective payment systems. Admittedly, CMS has developed a series of adjustments for new technology. However, these mostly provide price supports for new services and technologies that are not well priced as products come to the market. After volume increases and costs are better known, the relative MS-DRG prices for new technology should be as fair as prices for older technologies.

In the end, prospective payment systems put pressure on resource use within each MS-DRG. This forces device manufacturers to set their prices with some care and set their prices with consideration of medical value. While CMS does not price to value, each hospital can pay for value within a given MS-DRG. These effects may be as important, if not intentional, as the "underpricing" presented in the paper.

Is the work clearly and accurately presented and does it cite the current literature? Partly

Is the study design appropriate and is the work technically sound? Partly

Are sufficient details of methods and analysis provided to allow replication by others? 
Yes

If applicable, is the statistical analysis and its interpretation appropriate?

Partly

Are all the source data underlying the results available to ensure full reproducibility? Yes

Are the conclusions drawn adequately supported by the results? Partly

Competing Interests: No competing interests were disclosed.

Reviewer Expertise: Evaluating Medicare's various PPS policies

I confirm that I have read this submission and believe that I have an appropriate level of expertise to confirm that it is of an acceptable scientific standard, however I have significant reservations, as outlined above.

The benefits of publishing with F1000Research:

- Your article is published within days, with no editorial bias

- You can publish traditional articles, null/negative results, case reports, data notes and more

- The peer review process is transparent and collaborative

- Your article is indexed in PubMed after passing peer review

- Dedicated customer support at every stage

For pre-submission enquiries, contact research@f1000.com 